\title{
La extensión de la UNA y su impacto en el desarrollo de las comunidades rurales: Aportes al desarrollo autogestionario de la comunidad de Barra de Colorado, Pococí, Limón
}

Esteban Arboleda-Julio

Universidad Nacional

Heredia, Costa Rica earbole@una.cr

Diego Aguirre-Rosales

Universidad Nacional

Heredia, Costa Rica

daguirre@una.ac.cr

Recibido: 09/ 09 /2014 Aceptado: 06/30/2016

Resumen: Como parte de los procesos de extensión de la Universidad Nacional (UNA), la Escuela de Ciencias Agrarias (ECA) participó en un proyecto ejecutado en forma conjunta con la Universidad de Costa Rica (UCR), la Universidad Estatal a Distancia (UNED) y el Instituto Tecnológico de Costa Rica (ITCR). Dicho proyecto fue financiado por CONARE como parte de una iniciativa para el desarrollo regional. La ECA participó, principalmente, en la formulación el Plan de Desarrollo Local 2011-2016 de la comunidad de Barra de Colorado, del distrito de Barra de Colorado, cantón de Pococí, provincia de Limón. Este plan de desarrollo se convirtió en una herramienta que permitió a la comunidad la negociación de recursos y servicios ante la institucionalidad pública, esto permite abrir oportunidades y beneficios que han anhelado por mucho tiempo las familias de la comunidad, ya que siempre han estado en condición 
Revista Universidad en Diálogo • Vol. 6, N. 2 2, Julio-diciembre 2016, pp. 205-240

ISSN 2215-2849 • EISSN: 2215-4752

DOI: http://dx.doi.org/10.15359/udre.6-2.12

de marginación, exclusión y olvido de los beneficios de la municipalidad y de la mayoría de instituciones del Estado. Tal situación, sin duda alguna, es una de las principales causas del alto índice de pobreza en la comunidad, debido a que no se tiene acceso a servicios básicos de las instituciones y a fuentes de empleo estables, lo cual no permite a las familias mejorar su calidad de vida. Esto trae como consecuencia que la comunidad de Barra de Colorado este entre los cinco distritos más pobres del país, tal y como lo refleja el Índice de Desarrollo Social de MIDEPLAN, 2007. El Plan Desarrollo de la Comunidad de Barra de Colorado consta de un diagnóstico participativo sobre la situación de los sectores estratégicos de la comunidad. Luego se efectuó un análisis integral de la situación de la comunidad, posteriormente se realiza una proyección de la situación de la comunidad, para ello se construyen dos escenarios en el tiempo: pesimista y optimista. Se proyecta la visión de desarrollo que se desea alcanzar (se integran los principios, misión, objetivos y políticas). Luego se establece una serie de componentes estratégicos (dentro de los cuales se establecen los proyectos requeridos para la solución de la problemática que limita el desarrollo de las familias del cantón). Finalmente, se establece la estrategia de ejecución y seguimiento participativo del plan, en donde deben involucrarse las organizaciones comunales, la municipalidad, instituciones estatales, las universidades públicas y otros entes, en forma coordinada, para gestionar soluciones a la problemática que no ha permitido el desarrollo de las familias de la comunidad de Barra de Colorado. Para realizar el proceso de gestión del Plan de Desarrollo, se toma como base la propuesta de CONARE definida como Iniciativa Interuniversitaria de Desarrollo de la Región Huetar Atlántica, la cual asegura la asesoría que hasta ahora ha brindado la Escuela de Ciencias Agrarias, Universidad Nacional (UNA), la participación de la Universidad Estatal a Distancia (UNED), la Universidad de Costa Rica (UCR) y el Instituto Tecnológico de Costa Rica. (ITCR). Así mismo, la organización comunitaria de Barra de Colorado deberá seguir realizando la gestión del Plan de Desarrollo, donde deberá promover y concretar todo un trabajo de articulación y coordinación interinstitucional estatal y de otras organizaciones y entes de la sociedad civil, para integrar recursos económicos, esfuerzos humanos y logísticos para poder alcanzar los objetivos propuestos en el Plan de Desarrollo.

Palabras clave: Plan de Desarrollo Local, comunidad de Barra de Colorado, Universidad Nacional, CONARE, Índice de Desarrollo Social.

Abstract: As part of the process of extension of the National University (UNA) School of Agricultural Sciences (ECA) participated in a project which was implemented jointly University of Costa Rica (UCR), the State Distance University (UNED) and the Technological Institute of Costa Rica (ITCR). This project was funded by CONARE as part of an initiative for regional development. ACE 
itself was mainly participating in the participatory formulation of the Local Development Plan 2011-2016 of the community of Barra de Colorado, district of Barra de Colorado, Pococí province of Limon. This Development Plan became a tool that allowed the community to the negotiation of resources and services to public institutions, it can open opportunities and benefits have always been long cherished by the families of the community, as they have always been in condition of marginalization, exclusion and neglect of the benefits of the municipality and most state institutions, this is certainly one of the main causes of the high rate of poverty in the community, because there is no access to Basic services institutions and stable sources of employment, which does not allow families to improve their quality of life, this results that the community of Barra de Colorado this among the five poorest districts of the country, as we It reflects the Social Development Index of 15.9 according to MIDEPLAN, 2007. The Development Plan of the Community of Barra del Colorado, consists of a participatory assessment on the status of the strategic sectors of the community. A comprehensive analysis of the situation of the community is then performed, then projecting the situation of the community, to do this two scenarios are built over time is performed: Pessimistic and optimistic. The vision of development to be achieved (the principles and integrated, mission, objectives) is projected. A series of strategic components are then established (within which the projects required to solve the problems that limit the development of families in the canton are established). Finally, the implementation strategy of the plan and participatory monitoring, where community organizations should participate, the municipality, state institutions, public universities and other bodies established, which in a coordinated manner to perform management solutions to the problem which has prevented the development of families in the community of Barra de Colorado. To make this process management, implementation and evaluation of the Development Plan, the proposed set to CONARE Interuniversity Development Initiative Huetar Atlantic Region, which ensures taken as a basis for a specified time with the advice that has so far provided School of Agricultural Sciences, National University (UNA), the participation of the State Distance University (UNED), the University of Costa Rica (UCR) and the Costa Rica Institute of Technology. (ITCR), likewise, the community organization of Barra de Colorado should continue to undertake the management of the Development Plan which should promote and realize a whole work for coordination and other inter-governmental organizations and civil society entities to integrate economic, human and logistical efforts to achieve the goals set in the Development Plan.

Keywords: Local Development Plan, a community of Barra del Colorado National University, CONARE, Social Development Index. 
Revista Universidad en Diálogo • Vol. 6, N. 2, Julio-diciembre 2016, pp. 205-240

ISSN 2215-2849 • EISSN: 2215-4752

DOI: http://dx.doi.org/10.15359/udre.6-2.12

\section{Introducción}

Como parte de los procesos de extensión de la Universidad Nacional (UNA), la Escuela de Ciencias Agrarias (ECA) participó en un proyecto ejecutado en forma conjunta con la Universidad de Costa Rica (UCR), la Universidad Estatal a Distancia (UNED) y el Instituto Tecnológico de Costa Rica (ITCR). Dicho proyecto fue financiado por CONARE como parte de una iniciativa para el desarrollo regional. La ECA participó, principalmente, en la formulación el Plan de Desarrollo Local 2011-2016 de la comunidad de Barra de Colorado, del distrito de Barra de Colorado, cantón de Pococí, provincia de Limón.

El distrito de Barra de Colorado está ubicado en la parte Norte del cantón de Pococí, limita al Noreste con el mar Caribe y al norte con Nicaragua. Ambos pueblos cuentan con más de 1.700 habitantes. Territorialmente, es el distrito más grande del cantón con una extensión de 85.741,32 Ha, sin embargo, solo tiene el 3\% de la población total de Pococí.

Uno de los principales problemas se relaciona con los componentes del Índice de Desarrollo Social, el cual es el quinto más bajo de todos los distritos del país $(15,8)$. Aunado a esta problemática, se presentan más factores negativos como: nulas posibilidades de titulación de tierras, niveles de ingresos familiares muy bajos, carencia de fuentes de empleo estables, dependencia de la pesca artesanal, bajo o casi nulo poder político en la municipalidad y en otras instancias, malas vías de comunicación, bajo nivel organizacional, alta inmigración, entre otros. Los efectos son obvios: no hay capacidad de crédito, pocas fuentes de empleo, salarios de subsistencia, alto costo de vida; poca capacidad de negociación y exigencia, poco interés de las autoridades, baja calidad de servicios públicos y alta contaminación del ambiente (por razones exógenas y endógenas).

En general, las actividades productivas son: la agricultura, la pesca para consumo y venta de excedentes y, en menor escala, el turismo principalmente de pesca deportiva. La principal fuente de ingresos en Barra del Colorado es la pesca, actividad que es estacional debido a las vedas y malas condiciones ambientales. Vale recalcar, que el Gobierno no cuenta con subsidios para los pescadores que les den sustento en estas temporadas donde no se puede pescar. Además, existen pocas oportunidades de empleo y de mejoramiento de su calidad de vida, razón por la cual es necesario apoyar alternativas socio productivas que permitan impulsar el desarrollo de la localidad.

Los pescadores, como muchos otros grupos relacionados a la actividad agroalimentaria, no escapan de la problemática de mercadeo y comercialización; 
pues al ser la pesca estacional no pueden garantizar al consumidor, restaurante o establecimiento comercial un abastecimiento del producto constante durante todo el año. Dicho escenario y la falta de infraestructura, equipo y conocimiento en manipulación y valor agregado de los alimentos, hacen que el pescador dependa de la venta rápida del producto fresco a intermediarios, debido a la poca vida útil del mismo. Por otra parte, los períodos pico de pesca provocan una sobreoferta de pescado o crustáceos en el mercado, generando una caída en los precios de venta al intermediario. La falta de organización de los pescadores en estos casos agrava la situación, ya que se genera competencia entre ellos mismos, la cual solo beneficia el intermediario.

Algunos pobladores de Barra del Colorado ocasionalmente trabajan en actividades turísticas, puesto que en la zona existe una afluencia de turismo de pesca deportiva, actividad que genera empleos ocasionales. La falta de fuentes de ingreso se debe en gran parte al déficit de capital social, el cual se fomentará mediante la promoción del desarrollo local y el emprendimiento de actividades productivas.

Actualmente, las familias enfrentan otras dificultades que no les permiten alcanzar niveles de desarrollo adecuados, entre estos problemas se encuentran los de índole legal, ya que tiene tres leyes que los perjudican: la Ley que regula el ámbito marino terrestre, la Ley de posesión territorial de JAPDEVA y la Ley que declara refugio de vida silvestre al territorio donde se encuentra ubicada la comunidad de Barra de Colorado. Esta situación determina que las familias no puedan titular sus propiedad; además, les impide construir obras nuevas o explotar los recursos naturales a su alrededor, inclusive han sido objeto de desalojo por parte de las autoridades.

Con base en este entorno de desequilibrio social, económico, ambiental, organización y legal, es que se ha promovido la formulación participativa del Plan de Desarrollo Local, por medio del cual se tiene proyectado alcanzar un mejor nivel de desarrollo de las familias de la comunidad. Con este proyecto también se busca el fortalecimiento de las capacidades sociales de los integrantes de las organizaciones, de las instituciones estatales y de otros entes, para que ejecuten y realicen -en forma coordinada- el seguimiento del proceso de trabajo en el ámbito comunitario-distrital y en otros ámbitos donde se requiera, para alcanzar los objetivos establecidos en el Plan de Desarrollo.

\section{Objetivo general}

Socializar los resultados de la formulación y gestión del Plan de Desarro1lo, el cual permitió orientar el quehacer de las organizaciones de Barra de 
Colorado, la coordinación de instituciones del Estado y la municipalidad, para ordenar y mejorar el uso de los recursos (naturales, humanos, financieros y materiales), así como asegurar su uso eficiente y eficaz, en beneficio de la calidad de vida de toda la población de Barra de Colorado, bajo un enfoque de desarrollo humano, equitativo y sostenible.

\section{Capítulo 1: Metodología}

La formulación y ejecución de un proceso de desarrollo humano, sostenible y equitativo de un territorio, implica una serie de premisas fundamentales que se deben aplicar. A continuación se resumen las siguientes:

- Prepararse para desarrollar un gran trabajo de promoción de las personas y sus organizaciones, para que participen en forma consciente, activa y amplia, lo cual se logra al promocionar y educar a la ciudadanía.

- Elaborar un marco teórico-conceptual, estratégico y metodológico, que permita formular científicamente un proceso autóctono de desarrollo humano, sostenible y equitativo; en donde se establezca la organización del proceso, la participación de los actores, sus responsabilidades en los procedimientos y dinámicas de trabajo.

- Aplicar con precisión conocimientos metodológicos para elaborar el diagnóstico microregional (elaboración de antecedentes, identificación y evaluación de problemas, necesidades y fortalezas, proyectar la situación).

- Planificar en forma participativa un marco de referencia orientador.

- Presupuestar recursos y responsables de las acciones.

- Elaborar, de forma concreta y realista, la estrategia de ejecución y seguimiento participativo (control-ajuste, evaluación-retroalimentación, rendición de cuentas-toma de medidas y sistematización).

Los puntos anteriores, resultan indispensables para aspirar a ese mejoramiento integral de la calidad de vida de las personas en equilibrio con su entorno.

En la generación de un modelo de desarrollo humano, sostenibley equitativo, se reconoce la historia y los aspectos culturales, las necesidades prioritarias por parte de los mismos actores de la sociedad civil, y la proyección de la construcción participativa de las soluciones. El modelo genérico implica varios momentos procésales de profundización de la investigación de la realidad, para plantear las acciones y promover el desarrollo sostenible de un territorio o una microrregión. 


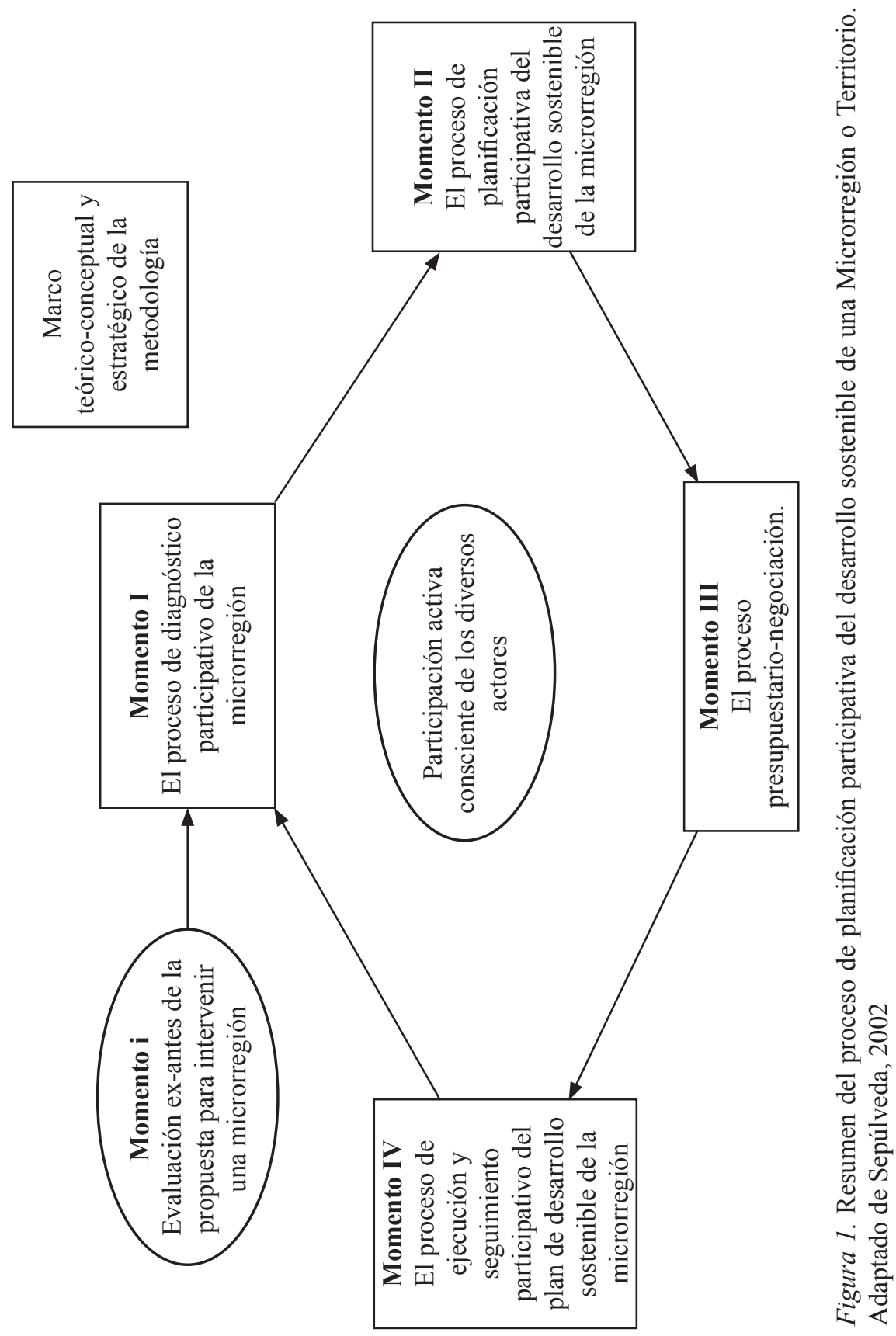


Revista Universidad en Diálogo • Vol. 6, N. 2 2, Julio-diciembre 2016, pp. 205-240

ISSN 2215-2849 • EISSN: 2215-4752

DOI: http://dx.doi.org/10.15359/udre.6-2.12

Sinopsis del contenido del modelo genérico del proceso de Planificación del Desarrollo Sostenible de una Microrregión (PDSM)

A continuación se presenta un resumen general de los momentos, etapas, fases que se aplican en el proceso de PDSM.

\begin{tabular}{ll}
\hline \multicolumn{1}{c}{ Aspecto del } & \multicolumn{1}{c}{ Descripción } \\
Modelo PDSM & \\
\hline Momento i & $\begin{array}{l}\text { Proceso de diagnóstico participativo de la microregión } \\
\text { como parte proceso de planificación del DSM }\end{array}$ \\
& I Etapa: Proceso ampliado de promoción e integración de \\
& los diferentes actores en la formulación participativa del Plan \\
& de Desarrollo Microregional: \\
& Primera fase: Promoción e inducción del planteamiento \\
& Sobre la formulación participativa de un Plan de Desarrollo \\
& Microregional ante el Municipio y el Alcalde de la \\
& jurisdicción a la que pertenece la microregión. \\
& Segunda fase: Desarrollo de eventos micro-regionales para la \\
& promoción, inducción y concertación del planteamiento sobre \\
& la elaboración participativa de un Plan de Desarrollo Microre- \\
& gional, ante la ciudadanía, organización de la sociedad civil, en- \\
& tes estatales y no estatales y empresa privada de la microregión. \\
& Tercera fase: Fortalecimiento de la cobertura y represen- \\
& tatividad de los actores en la conformación de la estrategia \\
& organizativa para la formulación participativa del Plan de \\
& Desarrollo Microregional \\
& II Etapa: El análisis de los antecedentes de la microregión \\
& III Etapa: El análisis de la situación actual de la microregión \\
& Primera fase: Caracterización de la microregión \\
& Segunda fase: Desarrollo de eventos participativos con \\
& las organizaciones comunitarias: determinación, análisis y \\
priorización de la problemática de la microregión & Tercera fase: Comprobación de la hipótesis, evaluación e \\
& interpretación de la situación actual de la microregión \\
& Etapa IV: Proyección (prognosis) de la situación actual \\
& de la microrregión: construcción de escenarios (invariante, \\
\hline & \\
&
\end{tabular}




\section{Aspecto del \\ Descripción Modelo PDSM \\ Momento II La planificación estratégica del desarrollo sostenible de una microrregión}

I Etapa: Construcción participativa del marco filosófico orientador del proceso de desarrollo sostenible de la microrregión.

La construcción de:

- La visión del desarrollo de una microregión

- La misión

- Los valores

- Los objetivos generales

- Las políticas

II Etapa: Construcción de las acciones prioritarias estratégicas para alcanzar la imagen deseada.

\section{Construcción del componente estratégico para la dimensión (o sector) económico.}

La elaboración de proyectos integrados en el horizonte temporal de planeamiento.

III Etapa: Elaboración de la estrategia de ejecución y seguimiento participativo del plan de desarrollo sostenible de la microrregión (PDSM).

Estrategia de ejecución del plan PDSM

Estrategia de seguimiento integralparticipativo del PDSM 


\begin{tabular}{|c|c|}
\hline $\begin{array}{c}\text { Aspecto del } \\
\text { Modelo PDSM }\end{array}$ & Descripción \\
\hline \multirow[t]{4}{*}{ Momento III } & $\begin{array}{l}\text { Elaboración del presupuesto maestro y la estrategia de nego- } \\
\text { ciación recursos integrales para financiar el PDSM }\end{array}$ \\
\hline & I Etapa: Elaboración del presupuesto maestro del PDSM. \\
\hline & $\begin{array}{l}\text { II Etapa: Elaboración de la estrategia de negociación de } \\
\text { recursos integrales para financiar el PDSM. }\end{array}$ \\
\hline & $\begin{array}{l}\text { III Etapa: Validación participativa e integral de la formulación } \\
\text { del plan de desarrollo sostenible de la microrregión. }\end{array}$ \\
\hline \multirow[t]{5}{*}{ Momento IV } & $\begin{array}{l}\text { Implementación del proceso de gestión (ejecución y } \\
\text { seguimiento) participativa del plan de desarrollo sostenible } \\
\text { microregional (PDSM) }\end{array}$ \\
\hline & $\begin{array}{l}\text { Primera fase: Implementación de la estrategia de gestión } \\
\text { participativa del proceso de ejecución del PDSM. }\end{array}$ \\
\hline & $\begin{array}{l}\text { Segunda fase: Implementación del sistema de seguimiento } \\
\text { (control, evaluación, rendición de cuentas y sistematización) del } \\
\text { PDSM. }\end{array}$ \\
\hline & $\begin{array}{l}\text { II Etapa: La consolidación del proceso de gestión del PDSM: } \\
\text { elaboración de la estrategia de mejoramiento del PDSM. }\end{array}$ \\
\hline & $\begin{array}{l}\text { Primera fase: Establecimiento de una estrategia superior de } \\
\text { promoción y motivación de la participación ciudadana en la } \\
\text { toma de decisiones en el proceso de gestión del PDSM. }\end{array}$ \\
\hline
\end{tabular}

Segunda fase: Elaboración y ejecución participativa de la estrategia de actualización del PDSM.

\section{Capítulo 2: Resultados y discusión}

\section{Planificación del desarrollo autogestionario de la comunidad de Barra de Colorado 2011-2016}

Para efectos de conceptualizar el tipo de desarrollo que se promueve en la comunidad de Barra de Colorado, se requiere buscar un desarrollo humano con equidad y sostenibilidad. Este se entiende como un proceso armonioso en el que las personas se ayudan a sí mismas y a los demás. La ayuda se da desde la relación con el mercado hasta los diversos servicios públicos 
que fortalecen la capacidad (conocimientos) de las personas y los demás actores que interactúan en la sociedad civil, asegurando que al satisfacer las necesidades del presente, no se comprometa la capacidad de las futuras generaciones. Lo anterior implica tener claros los siguientes conceptos.

Humano: Este aspecto se entiende como la promoción hacia una satisfacción plena de las necesidades básicas, y el desarrollo progresivo de todas las potencialidades del ser humano, sin distingo de razas, credo o nacionalidad, garantizando el respeto de la dignidad humana y la justicia social.

Equitativo: Este aspecto se entiende como la promoción de cuatro aspectos integrales y fundamentales como lo son:

Social: Garantizar progresivamente la equidad de género, mediante la satisfacción plena de las necesidades y el mejoramiento integral de las condiciones de vida de los seres humanos que forman la familia.

Económico: Oportunidades de acceso al trabajo, a la generación de riqueza, a su movilidad en el acceso a los servicios integrales de calidad de las personas.

Cultural: Fortalecimiento de identidad cultural.

Ecológica: Ambiente sano y una vida en armonía, con la conservación de la biodiversidad y recursos naturales.

La sostenibilidad: Este punto se entiende como la promoción de tres aspectos integrales y fundamentales como lo son:

Económica: Promueve un crecimiento económico con eficiencia, competitividad y eficacia de la municipalidad, las instituciones públicas y privadas.

Social: Garantizar la participación democrática de la ciudadanía, el empoderamiento y cohesión de la organización en la sociedad, la consolidación de su identidad (valores, costumbres, tradiciones recreativas y deportivas).

Ecológica: Se promueve la conservación de los recursos naturales, por medio de una planificada capacidad de aprovechamiento de su uso y la preservación de la biodiversidad, sin comprometer lo que le pertenece a las futuras generaciones. 
Revista Universidad en DiÁlogo • Vol. 6, N. ํㄹ 2, Julio-diciembre 2016, pp. 205-240

ISSN 2215-2849 • EISSN: 2215-4752

DOI: http://dx.doi.org/10.15359/udre.6-2.12

\section{Capítulo 3: Construcción del marco filosófico orientador del plan de desarrollo local}

Congruente con lo analizado en el diagnóstico, se procede a establecer el marco orientador que permitirá a la Asociación de Desarrollo Integral de Barra de Colorado, a la municipalidad y a las instituciones una gestión clara para ejecutar las acciones establecidas en el Plan de Desarrollo en los próximos cinco años.

\section{Construcción de la imagen objetivo (visión de comunidad que se desea alcanzar)}

La visión que orientará el Plan de Desarrollo se proyecta en tres grandes aspiraciones:

I. Un tipo de desarrollo entendido como un proceso educativo integral que le permita a los sectores sociales tener las capacidades, para desarrollar con eficiencia y eficacia los procesos gestión del desarrollo socioeconómico y productivo, y de esta forma generar un bienestar humano integral, sostenible tanto en el ámbito económico, como en el psicológico y espiritualmente. En donde se promueva la solidaridad y la fraternidad, el aseguramiento de la equidad de género en la distribución de los beneficios generados y en las formas de participar y compartir la responsabilidad que implican los procesos de gestión del desarrollo social y productivo-económico.

II. La generación y desarrollo de diversas alternativas de producción (bienes y servicios) con capacidad de competitividad integral: socio-productiva, de armonía con los recursos naturales y el ambiente, que asegure la rentabilidad económica, esté acorde con las exigencias del mercado (alta calidad, convertibilidad de los productos, cumplimiento de normas ambientales, sanitarias y laborales, y de continuidad del flujo del producto), genere alto valor agregado y su distribución beneficie proporcionalmente a los actores generadores iniciales de la cadena alimentaria, y finalmente que los procesos productivos se fundamenten en el uso de una tecnología creativa que integre, en la medida de lo posible, el conocimiento autóctono e innovación tecnológica avanzada.

III. Una capacidad de gestión de avanzada de las organizaciones (organizaciones de base, empresarial, cámaras y otros actores económicos) las instituciones (estatales y no gubernamentales), y la municipalidad, que 
permita promover la coordinación, la administración y gerencia de los procesos requeridos para hacer efectiva una reconversión social, productivo-económica y un fortalecimiento empresarial para el desarrollo de las familias y organizaciones de productores de las comunidades.

\section{Construcción de la misión}

Formular y ejecutar un proceso participativo de desarrollo humano, equitativo y sostenible, que considere a los sectores de la sociedad civil susceptibles de ser potenciados en su capacidad integral, como personas con calidad de vida y como agentes productivo-económico dinamizadores del desarrollo social de las familias y de la comunidad, permitiendo generar y distribuir el valor agregado, para mejorar las condiciones socio productivas y económicas tales como:

Promoción y desarrollo de alternativas productivas de competitividad integral para los sectores productivos intra e inter comunidades del cantón y a nivel regional

Contribuir con un desarrollo balanceado (tomando en cuenta lo social, económico, ambiental) en el cantón y en la región.

Promover la democratización y equidad de la distribución de la riqueza.

Generación de empleo (aumento de empleos directos para el bienestar familiar y social).

Combatir y disminuir la pobreza, bajo un concepto de respeto de la capacidad de las personas para el trabajo.

Producir en forma sostenida una cantidad de bienes y servicios para el consumo nacional y para la exportación.

Un aumento de la PEA y una significativa participación en el PIB regional.

Renovar, integrar y aumentar la confianza en la eficiencia de las instituciones estatales y no estatales, lo cual permitirá fortalecer la sostenibilidad de las estructuras sociales locales y su integración a nivel micro-regional y regional, lo cual a su vez, permitirá - a manera de proceso- consolidar la integración y coordinación institucional y política, las cuales constituyen un eje fundamental para propiciar nuevos procesos que promuevan el desarrollo de los actores sociales comunales. 
Revista Universidad en Diálogo • Vol. 6, N. 2 2, Julio-diciembre 2016, pp. 205-240

ISSN 2215-2849 • EISSN: 2215-4752

DOI: http://dx.doi.org/10.15359/udre.6-2.12

\section{Construcción de los valores}

Los valores que se promueven son los siguientes:

La interiorización del PDCBC 2011-2016 como un proceso de educación integral de los sectores sociales de las comunidades (elementos básicos: aprender, entender, y aplicarlo bien).

La gestión coordinada entre ciudadanos-organización- la municipalidad y las instituciones.

El Proceso con enfoque de gestión y autodesarrollo humano, equitativo y sostenible.

El reconocimiento de la realidad integral de las familias de las comunidades y de su integración distrital y reconocimiento de la acción interinstitucional.

El rescate y la promoción de la solidaridad y la fraternidad entre los ciudadanos, las comunidades, los distritos y agentes que interactúan en la región.

La promoción de la tolerancia, la moral y el respeto por la diversidad de pensamiento y creencias de los seres humanos.

Una racionalidad sustantiva y la sostenibilidad en el manejo y uso de los recursos naturales.

La promoción de un trabajo organizado, ordenado, responsable regido por la honestidad y la rendición de cuentas a ciudadanía.

Promoción de procesos productivos con capacidad competitiva integral.

El bienestar integral del ser humano es lo fundamental del PDL-BC 2011216, en convivencia armónica con su medio.

\section{Construcción del objetivo general}

Orientar el quehacer de las organizaciones de Barra de Colorado, la coordinación de instituciones del Estado y la municipalidad, para ordenar y mejorar el uso de los recursos (naturales, humanos, financieros y materiales), así como asegurar su uso eficiente y eficaz, en beneficio de la calidad de vida de toda la población de Barra de Colorado, bajo un enfoque de desarrollo humano, equitativo y sostenible, en el cual se promueva la coordinación interinstitucional, el equilibrio, la solidaridad y la justicia en el acceso a los diversos servicios básicos y a las oportunidades que se generen según las 
dinámicas socio-productivas y económicas que se desarrollan en el espacio territorial de las comunidades de Barra de Colorado.

\section{Construcción de objetivos específicos del plan de desarrollo}

a) Establecer los lineamientos de planificación del desarrollo sostenible del distrito en el contexto de la ley que transforma en Refugio de Vida Silvestre, los cuales deben regir en el quehacer organizacional comunal, en toda institución pública y la municipalidad, durante los próximos 5 años.

b) Iniciar un proceso de desarrollo integral que permita minimizar los desequilibrios que se presentan intra e inter comunidades del distrito y de estas con el cantón, en lo referente a la toma de decisiones participativas, equidad en la inversión y en el acceso a oportunidades de producción, servicio y al disfrute de un medio ambiente y espacio vital, óptimo para la vida humana.

c) Promover la planificación en conjunto con la sociedad civil para orientar y optimizar los recursos de diferente tipo, que posee la municipalidad, las instituciones públicas, las organizaciones de las comunidades y otros entes, para mejorar con equidad y sostenibilidad el acceso a la infraestructura y los servicios de calidad: educación, la salud, la vivienda, la seguridad ciudadana, el fomento de la cultura, la recreación y el deporte, requeridos para satisfacer las necesidades de la población y así mejorar su calidad de vida.

d) Promover la planificación en conjunto con la sociedad civil para orientar y optimizar los diferentes recursos de la municipalidad, las instituciones públicas y las organizaciones de las comunidades y otros entes, para mejorar con equidad y sostenibilidad la generación y acceso a oportunidades de producción y de fuentes de empleo, que permitan aumentar el ingreso familiar y mejorar su calidad de vida.

e) Promover la planificación en conjunto con la sociedad civil, para orientar y optimizar los diferentes recursos de la municipalidad, las instituciones públicas, las organizaciones de las comunidades y otros entes, para mejorar con equidad y sostenibilidad el manejo y uso racional de los recursos naturales, el ambiente y el espacio territorial del cantón, para mejorar su calidad de vida.

Con estos objetivos se plantea como prioridad superior en el Plan de Desarrollo, debido a que el territorio este dentro de un Refugio de Vida Silvestre, el manejo, uso y conservación de los recursos naturales debe realizarse en 
Revista Universidad en Diálogo • Vol. 6, N. 2 2, Julio-diciembre 2016, pp. 205-240

ISSN 2215-2849 • EISSN: 2215-4752

DOI: http://dx.doi.org/10.15359/udre.6-2.12

forma racional, de manera que se garantice a perpetuidad la preservación de los recursos naturales biótico y abióticos, ya que estos son patrimonio de las futuras generaciones de nuestras comunidades.

\section{Construcción de la política local}

La política fundamental que orientará el quehacer de la Asociación de Desarrollo de Barra de Colorado, durante los próximos cinco años (Periodo 2011-2016) será: Mejorar el índice de Desarrollo Social (IDS).

De forma estricta, la Asociación de Desarrollo integral, la municipalidad y las instituciones, se avocarán todos sus esfuerzos a su alcance para pasar de un IDS 15,8 (MIDEPLAN, 2009), por medio de esta política, lo cual requiere múltiples esfuerzos de integración de las acciones para minimizar las desigualdades sociales y, a su vez, promover las potencialidades para el desarrollo social humano, equitativo y sostenible.

Esta política fundamental se sustenta en el estudio de MIDEPLAN (2009), el cual indica que el Distrito de Barra de Colorado ocupa el tercer IDS más bajo de toda la provincia de Limón y se ubica en los últimos cinco distritos con el IDS más bajo de todo el país. Por lo tanto, existe una gran cantidad de habitantes que no pueden satisfacer sus necesidades básicas, ya que no tienen oportunidad de acceso a una serie de servicios y generación de ingresos, lo que va en detrimento del bienestar familiar.

Para superar la problemática anterior, se realizarán todos los esfuerzos del concejo municipal, la ciudadanía, la organización comunal y las instituciones, para que en forma atinente, coherente y pertinente, se desarrollen acciones y se orienten los recursos hacia el logro de un desarrollo humano, equitativo y sostenible que garantice progresivamente el bienestar social de las familias de las comunidades del distrito.

El desarrollo no se puede ver por separado, es decir, las partes deben estar integradas y direccionadas hacia un mismo propósito, en este sentido, es que se han establecido una serie de políticas específicas que se promoverán en forma integral en el periodo 2011-2016.

\section{Enunciados de políticas de direccionamiento del plan de desarrollo de corto y mediano plazo}

a) Mejorar la eficiencia, eficacia y la participación con equidad de la ciudadanía en la deliberación y toma de decisiones importantes ante el 
Concejo municipal, para promover el desarrollo de las comunidades del distrito de Barra de Colorado.

b) Crear una comisión contralora ciudadana, con potestad moral y legal (derechos que tiene todo ciudadano costarricense de acudir a la instancia legal que establezca nuestro marco jurídico), para ejercer como ente fiscalizador del seguimiento Integral del PDL-BC2011-2016. Dicha comisión ejercerá el control y solicitará la evaluación y rendición de cuentas del Plan de Desarrollo anual, mediante una asamblea comunal ampliada. Sobre esta base, la Asociación de Desarrollo procederá a confeccionar los informes para la comunidad. Ahí podrá fundamentar las denuncias que correspondan, cuando algunas de las instancias institucionales, municipal u organizacionales no esté cumpliendo como está establecido en el plan de desarrollo local de Barra de Colorado.

c) Fomento y fortalecimiento de los procesos educativos, por medio de la consecución de un programa permanente de becas para apoyar el acceso de al sistema educativo de jóvenes de escasos recursos de la comunidad.

d) Orientar la toma de decisiones para que la inversión institucional pública, progresivamente se haga conforme a lo requerido por plan de desarrollo local.

e) Toda la inversión de la municipalidad en la comunidad deberá ser de conformidad con las prioridades establecidas en el plan de desarrollo.

f) Establecimiento de una estrategia de gestión que permita proyectar el desarrollo de la comunidad en el ámbito nacional e internacional, para atraer inversionistas y donaciones que faciliten desarrollo humano, equitativo y sostenible en el cantón.

g) Integración del cantón con los ejes logísticos de desarrollo regional y nacional, mediante una gestión que promueva la integración socio-productiva y económica de las comunidades del distrito. Esto permitirá gradualmente reducir las desigualdades en los servicios públicos. También promoverá el acceso de las comunidades a la inversión, a mayores oportunidades productivas y mayores fuentes de empleo. El enfoque de esta estrategia se centrará en un desarrollo en armonía con el medio ambiente.

h) Consecución de recursos de inversión para la implementación de un plan regulador que permita el ordenamiento marítimo-terrestre del distrito. 
i) Gestión para el saneamiento de la comunidad, por medio la consecución de recursos de inversión para la implementación de una red de alcantarillado y manejo de aguas negras y para la implementación, a medio plazo, de un relleno sanitario moderno, para el reciclaje y tratamiento de los desechos sólidos generados en la comunidad.

j) Fomento de una estrategia de integración de la comunidad con los ejes logísticos de desarrollo regional y nacional, mediante una gestión que promueva la integración socio-productiva y económica de los seis distritos y del cantón como tal. Esto permitirá gradualmente reducir las desigualdades en los servicios públicos. También promoverá el acceso del cantón a la inversión, a mayores oportunidades productivas y de acceso a mayores fuentes de empleo. El enfoque de esta estrategia se centrara en un desarrollo en armonía con el medio ambiente.

\section{Capítulo 4: Construcción de los componentes (acciones) estratégicas del PDCBC}

Los componentes estratégicos de un plan de desarrollo se definen como las grandes estructuras fundamentales, sobre las que se asienta la ejecución de las acciones definidas para alcanzar el desarrollo deseado. Estos componentes estratégicos están dimensionados sobre la base de las cinco dimensiones establecidas en el diagnóstico, las cuales se integran a partir de una diversidad de factores diagnosticados que interactúan y están altamente correlacionados como elementos necesarios para solucionar los problemas y promover el desarrollo deseado de los ciudadanos.

Además, se presenta la identificación de los proyectos para aquella problemática prioritaria que requiere solución, según cada componente estratégico y sus áreas específicas, lo cual fue concertado y acordado por los miembros de la comunidad. También es de relevancia destacar que esta problemática priorizada, se integró para facilitar la gestión de recursos requeridos para la ejecución de dichos proyectos.

En la figura 2 se presenta una síntesis general de los ejes transversales, la estructura y función de los componentes estratégicos establecidos, lo cual en su conjunto, facilita el entendimiento del cómo se concibe alcanzar de forma integral la imagen objetivo propuesta para el PDCBC 2011-2016. 

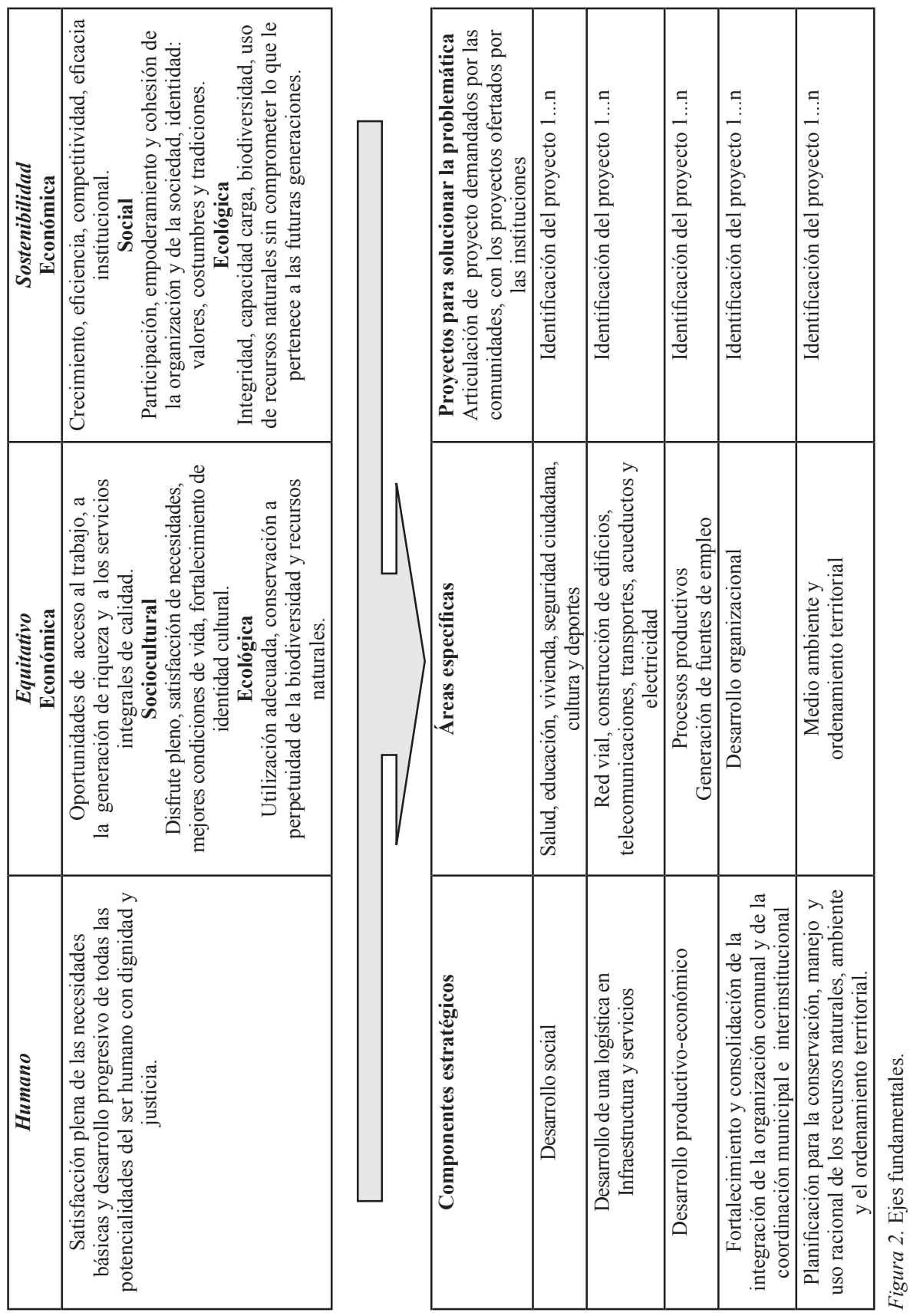
En cuanto al horizonte temporal, para la ejecución de los perfiles de proyectos identificados, se ha propuesto dos momentos de trabajo: un primer momento donde se ejecutan los proyectos priorizados para el corto y mediano plazo; y un segundo gran momento, en el cual se ejecuta una serie de perfiles de proyectos más ambiciosos y profundos en el mediano y largo plazo. Desde luego, como en todo proceso, ambos momentos de trabajo son etapas que se realizan en formas sucesivas, pero complementadas entre sí. La idea fundamental es que ello facilite la focalización de la coordinación de la acción e inversión de la municipalidad y las instituciones del Estado, y con ello, poder aspirar a tener un mayor impacto en el logro de los objetivos del plan de desarrollo.

\section{La identificación de los perfiles de proyectos para solucionar la proble- mática de la comunidad}

Como indicábamos anteriormente, para el primer momento de ejecución del PDCBC, se ha tomado como base las diferentes problemáticas identificadas, priorizadas e integradas, según las áreas de cada dimensión del desarrollo. A partir de esto, se procedió a identificar y describir la siguiente cartera de perfiles de proyectos, con el propósito de elaborar una síntesis de la identificación de perfiles de proyectos demandados por la comunidad, los cuales parten de la realidad de la situación de las familias.

La idea es que la institucionalidad, la municipalidad, así como otros entes puedan Identificar si algunos de los proyectos que están ofertando o desarrollan en algunas comunidades, se pueden articular al plan de desarrollo para resolver el problema identificado en el perfil de proyecto. Con esto se busca que la institucionalidad, la municipalidad, así como otros entes, puedan plantear nuevos proyectos para ser ejecutados y resolver el problema específico identificado en el perfil del proyecto. 


\title{
Componentes (acciones) estratégicas a desarrollar en el corto plazo
}

\author{
Componente: Desarrollo Social
}

\section{a. Identificación del proyecto demandado por la comunidad en el Área: Educación}

\begin{tabular}{|c|c|c|}
\hline Descripción de la problemática & Identificación del proyecto & Acción específica \\
\hline $\begin{array}{l}\text { En la comunidad se reportan } \\
\text { problemas como: baja calidad } \\
\text { en la educación (primaria y } \\
\text { secundaria), es politizada, faltan } \\
\text { programas de becas, carencia } \\
\text { de una adecuada infraestructura } \\
\text { y equipo para el proceso } \\
\text { educativo, altos niveles de } \\
\text { deserción y limitado acceso a la } \\
\text { educación. } \\
\text { Ausentismo de los maestros, } \\
\text { falta de orientador en el Colegio. }\end{array}$ & $\begin{array}{l}\text { Plan para la promoción y } \\
\text { fortalecimiento cualitativo y } \\
\text { cuantitativo de la calidad de } \\
\text { los procesos de la educación } \\
\text { formal en la comunidad. }\end{array}$ & $\begin{array}{l}\text { Gestionar ante el MEP, } \\
\text { JAPDEVA y la municipalidad } \\
\text { los recursos humanos, } \\
\text { técnicos, logísticos y } \\
\text { económicos para solucionar } \\
\text { integralmente esta } \\
\text { problemática. }\end{array}$ \\
\hline $\begin{array}{l}\text { En la comunidad se reportan } \\
\text { problemas de acceso a la } \\
\text { educación de niños y jóvenes por } \\
\text { falta de oportunidades de becas } \\
\text { para asistir a la educación primaria } \\
\text { y secundaria. Esto provoca altos } \\
\text { niveles de deserción estudiantil, lo } \\
\text { cual causa aumento de la vagancia, } \\
\text { la delincuencia y los embarazos } \\
\text { juveniles. }\end{array}$ & $\begin{array}{l}\text { Plan para la promoción y } \\
\text { fortalecimiento cualitativo y } \\
\text { cuantitativo de la calidad de } \\
\text { los procesos de la educación } \\
\text { formal en la comunidad. }\end{array}$ & $\begin{array}{l}\text { Gestionar ante el programa } \\
\text { AVANCEMOS del } \\
\text { MEP, el programa de } \\
\text { becas de JAPDEVA y } \\
\text { la municipalidad, más } \\
\text { recursos económicos para } \\
\text { tener un programa de becas } \\
\text { permanente en la comunidad. }\end{array}$ \\
\hline $\begin{array}{l}\text { En la comunidad existe } \\
\text { población sin concluir los } \\
\text { estudios de secundaria. Las } \\
\text { causas son múltiples: } \\
\text { a. Embarazos } \\
\text { b. Recursos insuficientes. } \\
\text { c. Ausencia de becas } \\
\text { d. Necesidad de trabajo (la pesca). }\end{array}$ & $\begin{array}{l}\text { Plan para la promoción y } \\
\text { fortalecimiento cualitativo y } \\
\text { cuantitativo de la calidad de } \\
\text { los procesos de la educación } \\
\text { formal en la comunidad. }\end{array}$ & $\begin{array}{l}\text { Gestionar ante el MEP el } \\
\text { establecimiento de un colegio } \\
\text { nocturno en la comunidad. }\end{array}$ \\
\hline $\begin{array}{l}\text { Actualmente, muchos quieren } \\
\text { terminar con sus estudios, pero no } \\
\text { hay acceso a la educación, ya que } \\
\text { no existe un colegio nocturno. }\end{array}$ & & \\
\hline
\end{tabular}

continúa 
Revista Universidad en Diálogo • Vol. 6, N. 2 2, Julio-diciembre 2016, pp. 205-240

ISSN 2215-2849 • EISSN: 2215-4752

DOI: http://dx.doi.org/10.15359/udre.6-2.12

\begin{tabular}{|c|c|c|}
\hline Descripción de la problemática & Identificación del proyecto & Acción específica \\
\hline $\begin{array}{l}\text { La comunidad se encuentra } \\
\text { dentro del Refugio de Vida } \\
\text { Silvestre; sin embargo, } \\
\text { la educación primaria } \\
\text { y la secundaria no está } \\
\text { contextualizada al entorno } \\
\text { ambiental. Esto genera } \\
\text { deficiencias conceptuales en } \\
\text { la formación educativa de } \\
\text { las personas, lo cual limita el } \\
\text { desarrollo de su vida en armonía } \\
\text { con el entorno. }\end{array}$ & $\begin{array}{l}\text { Plan para la promoción y } \\
\text { fortalecimiento cualitativo y } \\
\text { cuantitativo de la calidad de } \\
\text { los procesos de la educación } \\
\text { formal en la comunidad. }\end{array}$ & $\begin{array}{l}\text { Gestionar ante el MEP y } \\
\text { MINAET para implementar } \\
\text { en el colegio un enfoque } \\
\text { ambientalista congruente con } \\
\text { el entorno de la comunidad. }\end{array}$ \\
\hline $\begin{array}{l}\text { Tanto los jóvenes graduados } \\
\text { como los que actualmente cursan } \\
\text { el colegio no tienen acceso } \\
\text { a información y orientación } \\
\text { que les permita evaluar las } \\
\text { oportunidades que ofrecen las } \\
\text { universidades públicas para } \\
\text { que estudien alguna carrera. } \\
\text { Esta situación, en gran medida, } \\
\text { es la causa de que la única } \\
\text { opción de muchos jóvenes sea } \\
\text { trabajar como pescador, así } \\
\text { como de un incremento en el } \\
\text { desempleo y los embarazos de } \\
\text { las jóvenes. Todo esto repercute } \\
\text { en un aumento de las patologías } \\
\text { sociales, rezago social y la } \\
\text { pobreza extrema, cuyo impacto } \\
\text { es un subdesarrollo en la } \\
\text { comunidad. }\end{array}$ & $\begin{array}{l}\text { Plan para la promoción y } \\
\text { fortalecimiento cualitativo y } \\
\text { cuantitativo de la calidad de } \\
\text { los procesos de la educación } \\
\text { formal en la comunidad. }\end{array}$ & $\begin{array}{l}\text { Gestión para desarrollar una } \\
\text { feria vocacional universitaria } \\
\text { en la cual se incluya a } \\
\text { los estudiantes de Barra } \\
\text { de Colorado, Parismina, } \\
\text { Tortuguero y márgenes del } \\
\text { río San Juan. }\end{array}$ \\
\hline $\begin{array}{l}\text { Los estudiantes no han podido } \\
\text { organizarse para formar la } \\
\text { asociación de estudiantes del } \\
\text { colegio. Esto limita la gestión } \\
\text { de muchas acciones para su } \\
\text { beneficio. }\end{array}$ & $\begin{array}{l}\text { Plan para la promoción y } \\
\text { fortalecimiento cualitativo y } \\
\text { cuantitativo de la calidad de } \\
\text { los procesos de la educación } \\
\text { formal en la comunidad. }\end{array}$ & $\begin{array}{l}\text { Convocar a los estudiantes } \\
\text { para formar la asociación de } \\
\text { estudiantes del Colegio de } \\
\text { Barra de Colorado. }\end{array}$ \\
\hline
\end{tabular}




\begin{tabular}{|c|c|c|}
\hline Descripción de la problemática & Identificación del proyecto & Acción específica \\
\hline $\begin{array}{l}\text { En la comunidad deambulan } \\
\text { cerca de } 100 \text { estudiantes } \\
\text { egresados que no han tenido } \\
\text { acceso a la educación superior, } \\
\text { por múltiples causas, entre ellas } \\
\text { la falta de recursos económicos } \\
\text { para desplazarse a un recinto de } \\
\text { educación superior cercano. Esto } \\
\text { no solo limita el desarrollo de las } \\
\text { personas de Barra de Colorado, } \\
\text { sino también de los estudiantes } \\
\text { de Parismina, Tortuguero y otras } \\
\text { comunidades de las márgenes } \\
\text { del Río San Juan. }\end{array}$ & $\begin{array}{l}\text { Plan para la promoción y } \\
\text { fortalecimiento cualitativo y } \\
\text { cuantitativo de la calidad de } \\
\text { los procesos de la educación } \\
\text { formal en la comunidad. }\end{array}$ & $\begin{array}{l}\text { Gestión ante CONARE } \\
\text { para establecer un recinto } \\
\text { universitario permanente que } \\
\text { permita ampliar el horizonte } \\
\text { y oportunidades de estudio } \\
\text { a los más de } 100 \text { jóvenes y } \\
\text { extender dicha oportunidad } \\
\text { a los estudiantes de Barra } \\
\text { de Parismina, Tortuguero } \\
\text { y a otros de comunidades } \\
\text { cercanas. En la actualidad } \\
\text { la ADI-BC cuenta con el } \\
\text { terreno comunal propio } \\
\text { donde se puede desarrollar } \\
\text { dicha infraestructura. }\end{array}$ \\
\hline
\end{tabular}

\section{b. Identificación del proyecto demandado por la comunidad en el área: Salud}

\begin{tabular}{|c|c|c|}
\hline Descripción de la problemática & Identificación del proyecto & Acción específica \\
\hline $\begin{array}{l}\text { Históricamente, las comunidades } \\
\text { del sector Sur y Norte de Barra } \\
\text { de Colorado han estado en } \\
\text { total abandono, en cuanto al } \\
\text { servicio de agua potable, lo } \\
\text { cual posiciona como de carácter } \\
\text { de urgente la consecución de } \\
\text { un proyecto agua potable, que } \\
\text { permita el mejoramiento de } \\
\text { la salud de las familias de las } \\
\text { comunidades. }\end{array}$ & $\begin{array}{l}\text { Estrategia para el } \\
\text { mejoramiento de la calidad } \\
\text { al acceso de servicios para el } \\
\text { mejoramiento integral de la } \\
\text { salud y de la calidad de vida de } \\
\text { las familias de la comunidad. }\end{array}$ & $\begin{array}{l}\text { Gestión para la } \\
\text { formalización legal de } \\
\text { las ASADAS de Barra de } \\
\text { Colorado Sur y Norte, para la } \\
\text { consecución de un proyecto } \\
\text { agua potable para todas las } \\
\text { familias de la comunidad. } \\
\text { Gestión ante AyA para que } \\
\text { se realicen los estudios de } \\
\text { ingeniería para implementar } \\
\text { un acueducto a partir de la } \\
\text { naciente de cerro de Coronel. }\end{array}$ \\
\hline
\end{tabular}


Revista Universidad en Diálogo • Vol. 6, N. ํㄹ 2, Julio-diciembre 2016, pp. 205-240

ISSN 2215-2849 • EISSN: 2215-4752

DOI: http://dx.doi.org/10.15359/udre.6-2.12

\begin{tabular}{|c|c|c|}
\hline Descripción de la problemática & Identificación del proyecto & Acción específica \\
\hline $\begin{array}{l}\text { Se requiere mejorar } \\
\text { integralmente los servicios de } \\
\text { salud en forma permanente } \\
\text { debido a la siguiente situación: } \\
\text { a. La comunidad queda en } \\
\text { estado de indefensión al } \\
\text { suspenderse los servicios } \\
\text { médicos el fin de semana. } \\
\text { b. En el fin de semana, no } \\
\text { hay capacidad para atender } \\
\text { una emergencia, debido a } \\
\text { que no existe un servicio } \\
\text { de ambulancia para llevar } \\
\text { pacientes a Cariari. } \\
\text { c. No se dan servicios } \\
\text { especializados de salud en la } \\
\text { comunidad y cuesta mucho } \\
\text { salir a Cariari. } \\
\text { d. No se informa a la comunidad } \\
\text { sobre el estado de la salud de } \\
\text { las familias, de acuerdo a los } \\
\text { ASIS. } \\
\text { e. No existe un plan de } \\
\text { medicina preventiva familiar } \\
\text { comunitaria. } \\
\text { f. No se conoce el estado } \\
\text { alimentario y nutricional de la } \\
\text { comunidad. } \\
\text { g. Falta un programa permanente } \\
\text { de fumigación para combatir } \\
\text { la alta incidencia de } \\
\text { mosquitos, lo cual podría } \\
\text { generar epidemias. }\end{array}$ & $\begin{array}{l}\text { Estrategia para el } \\
\text { mejoramiento de la calidad } \\
\text { al acceso de servicios para el } \\
\text { mejoramiento integral de la } \\
\text { salud y de la calidad de vida de } \\
\text { las familias de la comunidad. }\end{array}$ & $\begin{array}{l}\text { Gestión para transformar } \\
\text { la clínica en un CASI, } \\
\text { que trabaje las } 24 \text { horas } \\
\text { durante toda la semana y se } \\
\text { pueda ofrecer los servicios } \\
\text { de cirugía ambulatoria, } \\
\text { emergencias, internamiento } \\
\text { para atender partos, } \\
\text { odontología y la realización } \\
\text { de exámenes de laboratorio, } \\
\text { rayos x, entre otros. } \\
\text { Gestión de recursos para la } \\
\text { reconstrucción de la plaza } \\
\text { y mejoramiento integral de } \\
\text { la cancha de basquetbol, } \\
\text { para el uso de múltiples } \\
\text { deportes en el sector Sur de } \\
\text { la comunidad. }\end{array}$ \\
\hline
\end{tabular}




\section{c. Identificación del proyecto demandado por la comunidad en el área: seguridad ciudadana}

\begin{tabular}{|c|c|c|}
\hline Descripción de la problemática & Identificación del proyecto & Acción específica \\
\hline $\begin{array}{l}\text { Históricamente, los sectores Sur } \\
\text { y Norte de Barra de Colorado, } \\
\text { por su condición fronteriza, } \\
\text { han tenido serios problemas de } \\
\text { seguridad tanto jurídica como } \\
\text { de vigilancia policial, así como } \\
\text { también se presenta una alta tasa } \\
\text { de inmigrantes ilegales. Todo } \\
\text { esto evidencia el carácter de } \\
\text { urgente la consecución de una } \\
\text { estrategia de seguridad ciudadana } \\
\text { que permita enfrentar el estado } \\
\text { de indefensión general para } \\
\text { mejorar la calidad de vida de las } \\
\text { familias de las comunidades. }\end{array}$ & $\begin{array}{l}\text { Estrategia para el } \\
\text { mejoramiento de la calidad } \\
\text { al acceso de servicios para } \\
\text { el mejoramiento integral de } \\
\text { la seguridad ciudadana, para } \\
\text { tener una mayor y calidad } \\
\text { de vida de las familias de la } \\
\text { comunidad. }\end{array}$ & $\begin{array}{l}\text { Gestión para la consecución } \\
\text { de recursos para la } \\
\text { construcción de un puesto } \\
\text { de vigilancia, equipamiento } \\
\text { y un mayor número de } \\
\text { efectivos de la policía para la } \\
\text { vigilancia en ambos sectores } \\
\text { de la comunidad. } \\
\text { Gestión para implementar } \\
\text { una agencia de migración en } \\
\text { la comunidad. }\end{array}$ \\
\hline
\end{tabular}

\section{d. Identificación del proyecto demandado por la comunidad en el área: recreación, deporte y cultura}

\begin{tabular}{|c|c|c|}
\hline Descripción de la problemática & Identificación del proyecto & Acción específica \\
\hline $\begin{array}{l}\text { Los sectores Sur y Norte de } \\
\text { Barra de Colorado han tenido } \\
\text { serios problemas de acceso } \\
\text { a espacios deportivos de } \\
\text { recreación y fomento cultural; } \\
\text { por lo tanto, se requiere } \\
\text { una estrategia integral que } \\
\text { promueva la recreación, el } \\
\text { deporte y la cultura, para } \\
\text { mejorar preventivamente la } \\
\text { salud, el combate al desempleo } \\
\text { y delincuencia, lo cual debe } \\
\text { impactar en un mejoramiento de } \\
\text { la calidad de vida de las familias } \\
\text { de las comunidades. }\end{array}$ & $\begin{array}{l}\text { Estrategia para el } \\
\text { mejoramiento de la calidad } \\
\text { vida al acceso de servicios } \\
\text { para el mejoramiento integral } \\
\text { de la recreación, el deporte y } \\
\text { la cultura, con el propósito de } \\
\text { mejorar la calidad de vida de } \\
\text { las familias de la comunidad. }\end{array}$ & $\begin{array}{l}\text { Gestión para la consecución de } \\
\text { recursos ante la municipalidad } \\
\text { de Pococí y otras instituciones, } \\
\text { para transformar la actual } \\
\text { plaza de la comunidad del } \\
\text { sector Norte en un parque } \\
\text { recreativo. } \\
\text { Gestión para obtener fondos, } \\
\text { con el propósito de comprar un } \\
\text { terreno para la instalación de } \\
\text { un polideportivo que permita } \\
\text { abrir opciones deportivas y } \\
\text { recreativas a los jóvenes y } \\
\text { adultos de las comunidades. } \\
\text { Gestión de recursos para la } \\
\text { reconstrucción de la plaza y } \\
\text { mejoramiento integral de la } \\
\text { cancha de basquetbol, para } \\
\text { el desarrollo de múltiples } \\
\text { deportes en el sector sur de la } \\
\text { comunidad. }\end{array}$ \\
\hline
\end{tabular}


Revista Universidad en Diálogo • Vol. 6, N. 2, Julio-diciembre 2016, pp. 205-240

ISSN 2215-2849 • EISSN: 2215-4752

DOI: http://dx.doi.org/10.15359/udre.6-2.12

\begin{tabular}{lll}
\hline Descripción de la problemática & Identificación del proyecto & Acción específica \\
\hline Existe una gran necesidad de & Estrategia para el & Elaborar una estrategia \\
vivienda, pero no se puede & mejoramiento de la calidad & que permita el acceso a los \\
acceder al bono porque familias & al acceso de servicios para el & recursos de las entidades para \\
no tienen título de propiedad, ya & mejoramiento integral de la & la erradicación y mejoramiento \\
que la tierra es de JAPDEVA, & vivienda mayor, que permita & de la infraestructura \\
además, la comunidad se & elevar la calidad de vida de & habitacional de las familias de \\
encuentra en un Refugio de Vida & las familias de la comunidad. & la comunidad. \\
Silvestre. & &
\end{tabular}

\section{Componente: Productivo-Económico}

\section{a. Identificación del proyecto demandado por la comunidad en el área: procesos productivos}

\begin{tabular}{|c|c|c|}
\hline Descripción de la problemática & Identificación del proyecto & Acción específica \\
\hline $\begin{array}{l}\text { La única fuente que se podría } \\
\text { denominar como proceso } \\
\text { de producción directo en la } \\
\text { comunidad, es la pesca artesanal, } \\
\text { la cual tiene el agravante de } \\
\text { que los precios que pagan los } \\
\text { intermediarios son muy bajos y, } \\
\text { en tiempo de veda, la gente se } \\
\text { queda sin generación de ingresos } \\
\text { y no existe un subsidio por parte } \\
\text { del Estado como sí existe en } \\
\text { otros lugares del país. }\end{array}$ & $\begin{array}{l}\text { Estrategia de } \\
\text { consolidación del sector } \\
\text { pesquero por medio } \\
\text { de la industrialización } \\
\text { y comercialización de } \\
\text { los productos del sector } \\
\text { pesquero, que permita el } \\
\text { mejoramiento del nivel de } \\
\text { ingreso y con ello tener } \\
\text { una mayor y calidad de } \\
\text { vida de las familias de la } \\
\text { comunidad. }\end{array}$ & $\begin{array}{l}\text { Gestión para establecer una } \\
\text { estrategia que permita la } \\
\text { organización de los pescadores } \\
\text { para realizar la industrialización } \\
\text { y comercialización de los } \\
\text { productos pesqueros de la zona, } \\
\text { de tal manera que este valor } \\
\text { agregado se pueda reflejar en } \\
\text { un mejoramiento de los niveles } \\
\text { de ingreso de las familias y un } \\
\text { impacto positivo en la calidad } \\
\text { de vida. }\end{array}$ \\
\hline
\end{tabular}




\begin{tabular}{lll}
\hline Descripción de la problemática & Identificación del proyecto & Acción específica \\
\hline $\begin{array}{ll}\text { No existen proyectos de } \\
\text { diversificación de bienes }\end{array}$ & Generación diversificada & Elaboración y consecución de \\
productivos, que permitan a & de fuentes de empleo & recursos para la implementación \\
las familias generar ingresos & el mejoramiento de & de una cartera de proyectos de \\
familiares y empleo a la & ingreso a las familias de la & artesanías, producción de huevo, \\
comunidad. & comunidad. & carne de pollo, cerdos, conejos, \\
& plantas medicinales, panadería, \\
& raíces y tubérculos, agricultura de \\
& autoconsumo, industrialización \\
& del coco, corte y confección, \\
& establecimiento de una mini- \\
& feria comunitaria rural, donde \\
las familias sean socias y se les \\
& permita generar fuentes de empleo \\
& e ingresos; lo cual se refleje en un \\
& mejoramiento de los niveles de \\
& ingreso de las familias y un impacto \\
& positivo en la calidad de vida.
\end{tabular}

\section{b. Identificación del proyecto demandado por la comunidad en el área: fuentes de generación de empleo}

\begin{tabular}{|c|c|c|}
\hline Descripción de la problemática & Identificación del proyecto & Acción específica \\
\hline $\begin{array}{l}\text { No existe un proyecto turístico } \\
\text { comunitario rural, que permita } \\
\text { a las familias ser propietarias y } \\
\text { generar ingresos y empleo en la } \\
\text { comunidad. }\end{array}$ & $\begin{array}{l}\text { Generación diversificada de } \\
\text { fuentes de empleo autócto- } \\
\text { nos que permitan el mejo- } \\
\text { ramiento de ingreso a las } \\
\text { familias de la comunidad. }\end{array}$ & $\begin{array}{l}\text { Elaboración y consecución de } \\
\text { recursos para la implementación } \\
\text { de un proyecto agro-eco-marino } \\
\text { turístico comunitario rural, donde } \\
\text { las familias sean socios acciona- } \\
\text { rios y generen fuentes de empleo } \\
\text { e ingresos, lo cual se refleje en un } \\
\text { mejoramiento de los niveles de in- } \\
\text { greso de las familias y un impacto } \\
\text { positivo en la calidad de vida. } \\
\text { Este proyecto se facilita, ya que } \\
\text { actualmente la asociación cuenta } \\
\text { con un terreno de } 10 \text { hectáreas, el } \\
\text { cual está en disposición de segre- } \\
\text { gar con tal finalidad. }\end{array}$ \\
\hline
\end{tabular}


Revista Universidad en Diálogo • Vol. 6, N. 2 2, Julio-diciembre 2016, pp. 205-240

ISSN 2215-2849 • EISSN: 2215-4752

DOI: http://dx.doi.org/10.15359/udre.6-2.12

\begin{tabular}{|c|c|c|}
\hline Descripción de la problemática & Identificación del proyecto & Acción específica \\
\hline $\begin{array}{l}\text { Algunas personas trabajan en } \\
\text { forma ocasional en los hoteles, } \\
\text { cuando hay temporada de pesca } \\
\text { deportiva, pero verdaderamente } \\
\text { no existe fuente de empleo para } \\
\text { los adultos y jóvenes que deser- } \\
\text { tan, sean graduados o no. }\end{array}$ & $\begin{array}{l}\text { Generación diversificada } \\
\text { de fuentes de empleo por } \\
\text { medio de la inversión ex- } \\
\text { trema en la comunidad, que } \\
\text { permita el mejoramiento de } \\
\text { ingreso a las familias de la } \\
\text { comunidad }\end{array}$ & $\begin{array}{l}\text { Gestionar para la elaboración } \\
\text { interinstitucional que permita } \\
\text { ofrecer estímulos para que la } \\
\text { empresa privada invierta en pro- } \\
\text { cesos de producción de bienes } \\
\text { y servicios: turismo comunita- } \\
\text { rio sostenible, agropecuarios, } \\
\text { agroindustriales, industriales, } \\
\text { artesanales y productos naturales } \\
\text { en la comunidad. } \\
\text { Creación de una estrategia de } \\
\text { capacitación permanente de la } \\
\text { mano de obra, acorde con los } \\
\text { requisitos de las nuevas fuentes } \\
\text { de empleo que se instalen en la } \\
\text { comunidad. }\end{array}$ \\
\hline
\end{tabular}

Componente: Planificación para la conservación, manejo y uso racional de los recursos naturales, ambiente y el ordenamiento territorial

\begin{tabular}{|c|c|c|}
\hline Descripción de la problemática & Identificación del proyecto & Acción específica \\
\hline $\begin{array}{l}\text { A pesar de que la comunidad } \\
\text { está dentro de un refugio } \\
\text { de Vida Silvestre, no existe } \\
\text { una asociación ambientalista } \\
\text { encargada de la Cuenca del Rio } \\
\text { Colorado ni que promueva la } \\
\text { preservación y el uso adecuado } \\
\text { de los recursos naturales, para } \\
\text { que las futuras generaciones } \\
\text { gocen de dichos recursos. }\end{array}$ & $\begin{array}{l}\text { Generación de una estrategia } \\
\text { integral para coadyuvar } \\
\text { en la gestión ambiental, } \\
\text { preservación, conservación y } \\
\text { uso adecuado de los recursos } \\
\text { naturales del Refugio de Vida } \\
\text { Silvestre en su contexto con la } \\
\text { comunidad. }\end{array}$ & $\begin{array}{l}\text { Desarrollar el proceso de } \\
\text { constitución legal de una } \\
\text { Asociación Ambientalista } \\
\text { encargada de la Cuenca del } \\
\text { Rio Colorado que promueva } \\
\text { la preservación y el uso } \\
\text { adecuado de los recursos } \\
\text { naturales, para que las futuras } \\
\text { generaciones gocen de dichos } \\
\text { recursos. } \\
\text { Desarrollar procesos } \\
\text { educativos y campañas para } \\
\text { mejorar la relación de los } \\
\text { habitantes con la gestión } \\
\text { ambiental, la preservación, } \\
\text { conservación y uso adecuado } \\
\text { de los recursos naturales del } \\
\text { Refugio de Vida Silvestre } \\
\text { en su contexto con la } \\
\text { comunidad. }\end{array}$ \\
\hline
\end{tabular}




\begin{tabular}{|c|c|c|}
\hline Descripción de la problemática & Identificación del proyecto & Acción específica \\
\hline $\begin{array}{l}\text { No existe un plan de } \\
\text { ordenamiento territorial } \\
\text { marítimo costero. Eso dificulta el } \\
\text { ordenamiento del territorio, por } \\
\text { el serio problema de que la tierra } \\
\text { está en manos de JAPDEVA, } \\
\text { lo cual tiene maniatadas a las } \\
\text { familias para obtener un título } \\
\text { de propiedad e instituciones } \\
\text { para hacer un ordenamiento } \\
\text { del territorio. Además, a la } \\
\text { comunidad le afectan otras } \\
\text { leyes como la marítimo- } \\
\text { terrestre y la ley del Refugio } \\
\text { de Vida Silvestre, la cual no } \\
\text { permite que se realicen obras de } \\
\text { infraestructura que afecten a la } \\
\text { flora y fauna. }\end{array}$ & $\begin{array}{l}\text { Generación de una estrategia } \\
\text { integral para ordenamiento } \\
\text { territorial que permita la } \\
\text { segregación de la propiedad } \\
\text { en manos de las familias de } \\
\text { la comunidad con una zona } \\
\text { de amortiguamiento que les } \\
\text { permita realizar actividades } \\
\text { socioeconómicas en armonía } \\
\text { con los recursos naturales del } \\
\text { Refugio de Vida Silvestre. }\end{array}$ & $\begin{array}{l}\text { Elaborar un proyecto de } \\
\text { ley para la segregación y } \\
\text { titulación de la tierra a favor } \\
\text { de las familias que cohabitan } \\
\text { en el Refugio Barra de } \\
\text { Colorado, el cual deberá ser } \\
\text { presentado ante la Asamblea } \\
\text { Legislativa por los diputados } \\
\text { de la región. } \\
\text { Presentar un recurso de } \\
\text { amparo por incumplimiento } \\
\text { de funciones de las } \\
\text { instituciones encargadas } \\
\text { de realizar el estudio de } \\
\text { ocupación en el Refugio de } \\
\text { Vida Silvestre, el cual es } \\
\text { emitido por la Procuraduría } \\
\text { General de la República. }\end{array}$ \\
\hline
\end{tabular}


Revista Universidad en Diálogo • Vol. 6, N. 2 2, Julio-diciembre 2016, pp. 205-240

ISSN 2215-2849 • EISSN: 2215-4752

DOI: http://dx.doi.org/10.15359/udre.6-2.12

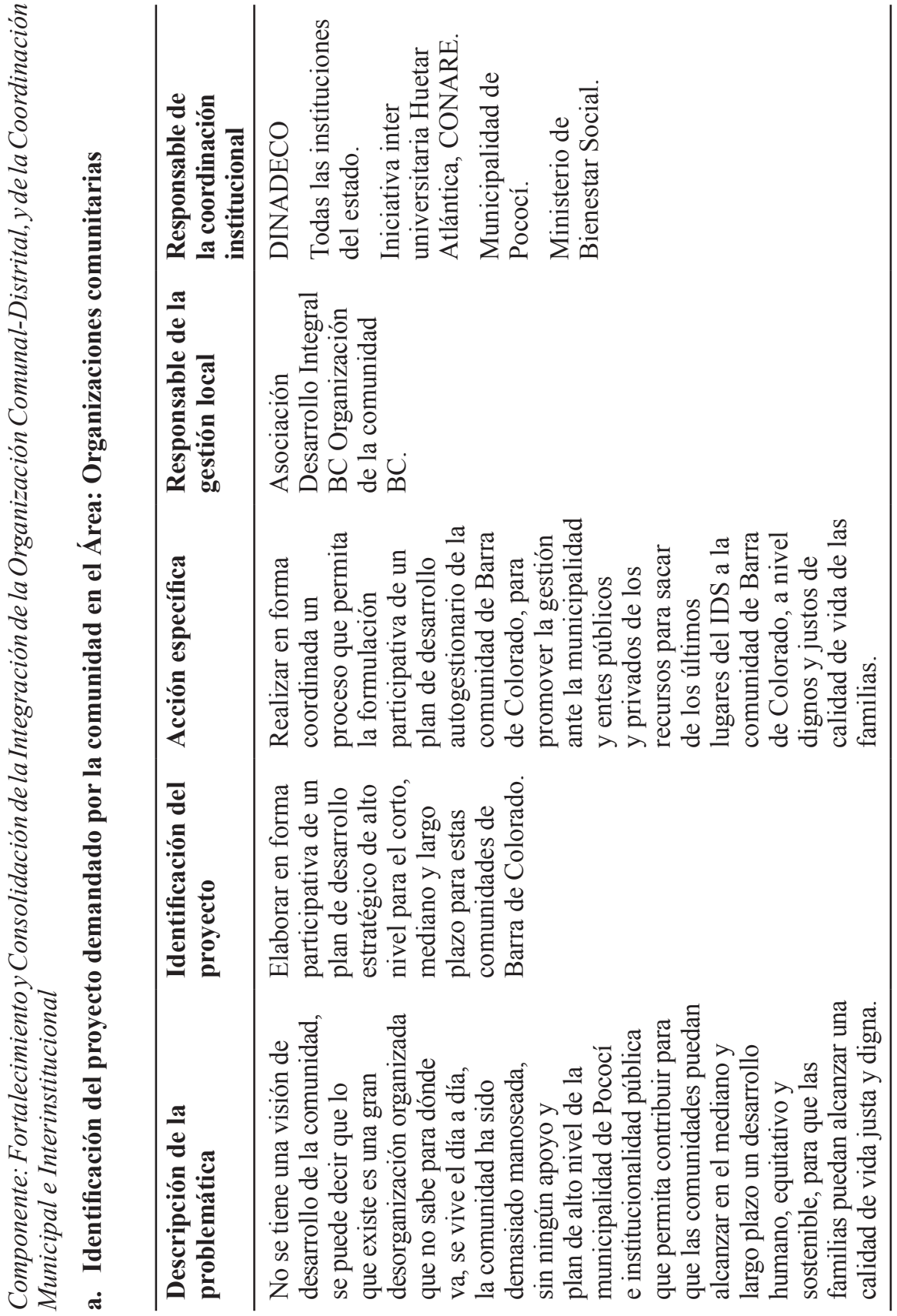




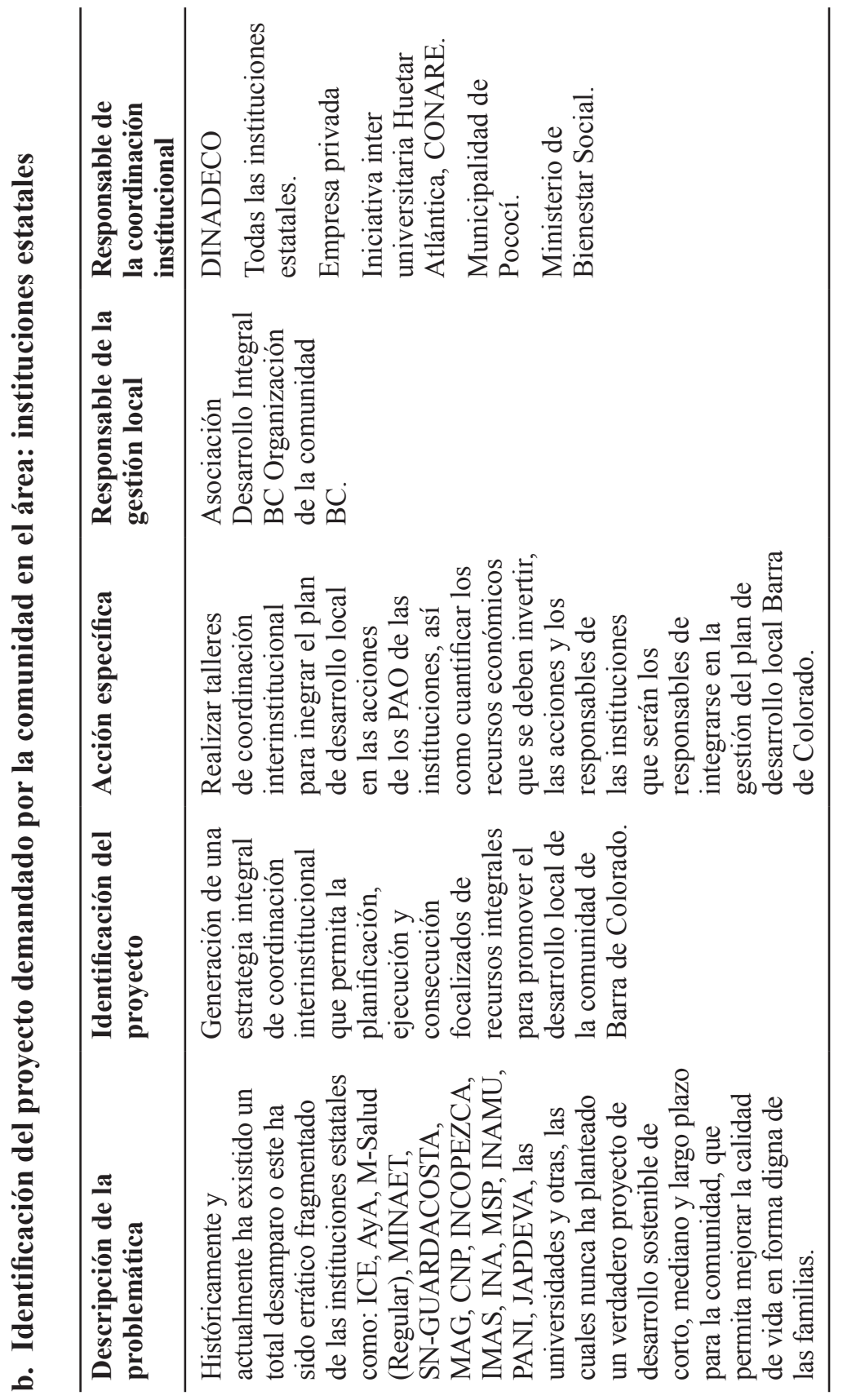


Revista Universidad en Diálogo • Vol. 6, N. 2 2, Julio-diciembre 2016, pp. 205-240

ISSN 2215-2849 • EISSN: 2215-4752

DOI: http://dx.doi.org/10.15359/udre.6-2.12

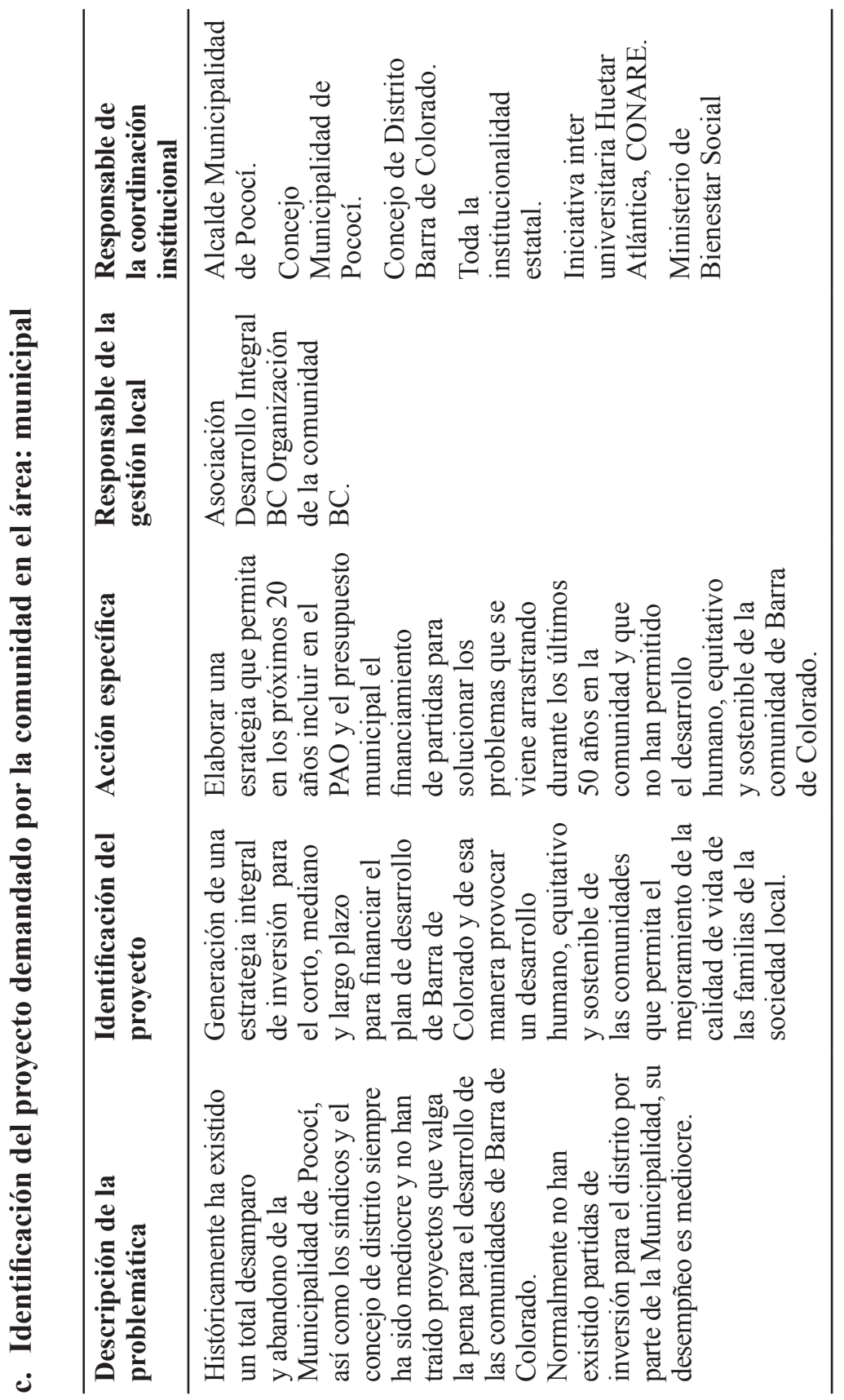




\section{Capítulo 5: Construcción de las estrategias organizativa y de seguimiento del Plan de Desarrollo Local Barra de Colorado}

\section{La estrategia de organizativa}

Consiste en que la Asociación de Desarrollo Integral de Barra de Colorado, se constituya, como lo indica la Ley, en el principal ente organizativo responsable de realizar la gestión del Plan de Desarrollo, en todos los ámbitos que se requieran tanto a nivel comunal, regional o nacional. Esta debe coordinar las acciones de las institucionales estatales, como en los ministerios, municipalidad, universidades, entre otros entes. La ADI debe garantizar a la comunidad el cumplimiento de sus deberes, para alcanzar los objetivos propuestos en el Plan de Desarrollo.

La ADI puede delegar algunas actividades a las organizaciones existentes, para que en forma coordinada se lleven a cabo las acciones requeridas. De igual manera, la ADI debe realizar una labor de coordinación con las instituciones, mediante la figura establecida en los Comités Cantonales de Coordinación Institucional (CCCI), vigentes en la actualidad.

\section{La estrategia de seguimiento del Plan de Desarrollo}

La ADI debe llevar un control de las acciones establecidas en el plan de desarrollo y, cuando la institucionalidad no responda, puede acudir a la Defensoría de los Habitantes y la Contraloría General de la República. Además, debe evaluar lo logrado en el plan y, de igual manera, realizar una rendición de cuentas a la comunidad de los resultados y en qué se ha fallado y cómo se corregirá. Durante los primeros años, la CRI-RHA asesora a la ADI en la operativización del plan, de igual manera la capacitará en la gestión de dicho plan.

Capítulo 6: Principales conclusiones sobre la situación de la comunidad barra de colorado en su relación con el Plan de Desarrollo como una herramienta para la proyección de un mejoramiento de la calidad de vida de las familias

a. La amplia participación activa, entusiasta y consciente de las personas y de la Asociación de Desarrollo Integral, así como las otras organizaciones en la elaboración del diagnóstico y en la formulación y gestión del Plan de Desarrollo Local, le dan una gran autenticidad, transparencia, confianza y esperanza a las familias, principalmente debido a que en la 
historia de la comunidad nunca se había contado con una herramienta de trabajo tan valiosa para promover un desarrollo humano, equitativo y sostenible de las familias del sector.

b. Es claro que el rezago en el desarrollo y pobreza humana de la comunidad es histórico y de origen multifactorial; en este sentido, el bajo Índice de Desarrollo Social (IDS) que arrastra históricamente a nivel provincial y de país, se comprueba con las grandes necesidades, carencias y limitantes que dan origen a la problemática identificada en el diagnóstico participativo de la comunidad.

c. Entre los graves problemas que causan el subdesarrollo de la comunidad y la pobreza de las familias están: la falta de procesos productivos y de fuentes de empleo que les permita generar un ingreso sostenible e inclusivo para vivir en forma más justa, digna y en armonía con su entorno del Refugio de Vida Silvestre.

d Como consecuencia de la pérdida de importancia económica de la comunidad como punto naviero comercial, así como del abandono o falta de apoyo sostenido de las instituciones estatales y de la municipalidad, las familias se encuentran en estado de indefensión general, lo cual provoca el desequilibrio y rezago social.

e. Existen historias de la convivencia de las familias que registran más de 100 años de ocupación de las tierras en que se asienta la comunidad; sin embargo, en la actualidad, tres leyes limitan su capacidad de subsistir: la ley marítimo-terrestre, la ley de posesión de las tierras por parte de JAPDEVA y la ley que crea el Refugio de vida Silvestre Barra de Colorado. Estas problemáticas jurídicas provocan un daño a nivel social, mental y espiritual en las personas, al sentirse que no tiene ningún futuro o más bien el futuro es que los desalojen de sus propiedades.

f. Como se aprecia, con todo lo anterior se logra dibujar un panorama difícil, donde la falta de oportunidades reales para el desarrollo de las familias es la constante en la comunidad, a ello se le une el flagelo de la droga y la delincuencia que no escapa de las problemáticas que causan las patologías sociales que tipifican a la pobreza en la comunidad. En la actualidad se vislumbra, al menos en principio, un horizonte, en el cual, al poseer un plan de desarrollo humano, equitativo y sostenible, la municipalidad e institucionalidad pública implementarán acciones que permitan a la familia salir progresivamente de ese estado de pobreza perversa en que se encuentran y pasar en el mediano plazo a un estado de bienestar digno y justo de vida. 


\section{Referencias}

CEDAL. Planificación y Desarrollo Regional y Local Latinoamericano, San José. Costa Rica. 1975.

Constitución Política de la República de Costa Rica. Presentado y actualizada por Gustavo Rivera Sibaja. Editec Editores. San José, Costa Rica. 2002.

Desarrollo de Base: Tema Especial: El Desarrollo Local. Revista de la Fundación Interamericana. Vol. 1. No. 1. 1997.

Delbecq. A. L. Van de Ven. A. y Gustafson D. H. Técnicas Grupales para la Planeación. Editorial Trillas. México, D.F. México. 1984.

Instituto Nacional de Estadística y Censo. Censo 2000. San José. Costa Rica. 2000.

Instituto Cooperativo Interamericano Planificación de la Organizaciones Populares. (ICI), Panamá, Panamá. 1994.

Frans Geilfus. 1997. 80 Herramientas para el Desarrollo Participativo: Diagnóstico, Planificación, Monitoreo y Evaluación. IICA, GTZ. San Salvador, El Salvador.

FAO. Manual para la Aplicación de la Metodología de Investigación Participativa entre Mujeres -IPEM- Oficina Regional de la FAO para América Latina y el Caribe. Santiago, Chile. 1993.

JAPDEVA. Plan de Desarrollo Regional Provincia de Limón 19992004/2009+. Documento I: Conceptualización y Diagnóstico. Limón, Costa Rica. 1999.

JAPDEVA. Plan de Desarrollo Regional Provincia de Limón 19992004/2009+. Documento II: Operacionalización del Plan. Limón, Costa Rica. 1999.

Ley de Planificación Urbana. San José. Costa Rica. 1995.

Ley de la Administración Financiera de la república y Presupuestos Públicos. Primera edición. San José, Costa Rica. IJSA. 2001.

Ley de Código Municipal. Comentado por Walter Cortéz H., Mariano Rodríguez A. y Sonia Camacho C.

Oscar J. H. Para Sistematizar Experiencias: Una Propuesta Teórica y Práctica (3a ed). San José. Costa Rica: Centro de Estudios y Publicaciones. ALFORJA. 1994. 
Revista Universidad en Diálogo • Vol. 6, N. 2 2, Julio-diciembre 2016, pp. 205-240

ISSN 2215-2849 • EISSN: 2215-4752

DOI: http://dx.doi.org/10.15359/udre.6-2.12

Proyecto Estado de la Nación en Desarrollo Humano Sostenible: Informe de la Auditoria Ciudadana sobre la Calidad de la Democracia. Volumen No.1. San José. Costa Rica. 2010

Sepúlveda, S. (2002). Desarrollo Sostenible Microregional: Métodos para Planificación Local. IICA-UNA. 313 p.

Sepúlveda. S.; Rodríguez. A., Echeverri, R. y Portilla, M. (2003). El Enfoque Territorial del Desarrollo Rural. San José, Costa Rica: IICA. 